\title{
Large primary cardiac tumor penetrating the right ventricle: 3-dimensional printing-based surgical planning
}

\author{
Eunji Kim, MD, ${ }^{\mathrm{a}}$ Won Kyung Pyo, MD, ${ }^{\mathrm{a}}$ Dong Hyun Yang, MD, PhD, ${ }^{\mathrm{b}}$ and Joon Bum Kim, MD, PhD, ${ }^{\mathrm{a}}$
} Seoul, South Korea

\footnotetext{
From the Departments of ${ }^{\mathrm{a}}$ Thoracic and Cardiovascular Surgery and ${ }^{\mathrm{b}}$ Radiology, Asan Medical Center, University of Ulsan College of Medicine, Seoul, South Korea.

Funded by a grant (2018-IT0404-1) from the Asan Institute for Life Sciences, Asan Medical Center, Seoul, Korea Disclosures: The authors reported no conflicts of interest.

The Journal policy requires editors and reviewers to disclose conflicts of interest and to decline handling or reviewing manuscripts for which they may have a conflict of interest. The editors and reviewers of this article have no conflicts of interest.

Received for publication Dec 5, 2020; accepted for publication Oct 29, 2021; available ahead of print Nov 9, 2021 Address for reprints: Joon Bum Kim, MD, PhD, Department of Thoracic and Cardiovascular Surgery, Asan Medical Center, University of Ulsan College of Medicine, 88, Olympic-Ro- 43-Gil, Songpa-Gu, Seoul 05505, Korea (E-mail: jbkim1975@amc.seoul.kr).

JTCVS Techniques 2022;11:37-40

2666-2507

Copyright (C) 2021 The Author(s). Published by Elsevier Inc. on behalf of The American Association for Thoracic Surgery. This is an open access article under the CC BY license (http://creativecommons.org/licenses/by/4.0/). https://doi.org/10.1016/j.xjtc.2021.10.061
}

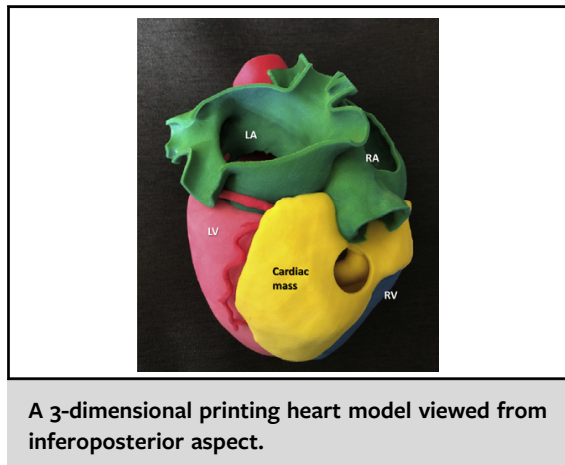

CENTRAL MESSAGE

A 3-dimensional printing model may be an important guiding tool for establishing surgical planning in complex cardiac tumors.

See Commentaries on pages 41 and 43 .
The primary cardiac tumor is extremely rare, constituting $0.3 \%$ to $0.7 \%$ of all cardiac tumors. ${ }^{1}$ Although complete resection is the mainstay in the management of cardiac tumors, it is technically challenging because of their extensiveness or involvement in vital structures. Preoperative imaging examinations including echocardiography and computed tomography scan provide information regarding the anatomical relationship between cardiac tumor and adjacent structures; however, it might be insufficient to determine operability. ${ }^{2}$ We report a case of a large primary cardiac tumor penetrating the right ventricle in which surgical planning was established based on 3-dimensional (3D) printing model.

\section{CASE REPORT}

A 33-year-old female patient was referred to our institution due to an incidentally found cardiac tumor. On transthoracic echocardiography, an echogenic mass at the inferoposterior right ventricular (RV) wall extending to the mitral annulus level was noted without deterioration of valvular or ventricular function (Figure 1, A). Computed tomography of the heart revealed a cardiac mass $(66 \mathrm{~mm} \times 70 \mathrm{~mm} \times 40 \mathrm{~mm})$ that, located at the inferior epicardial space, was penetrating and protruding into the RV chamber (Figure 1, $B-D$ ). Radiologic findings suggested a liposarcoma. For further understanding of spatial orientation and relation to adjacent structures, a 3D printing model was constructed using a gypsum-like cast model (Projet 460 printer and VisiJet PXL Core powder, VisiJet PXL clear binder and color bonds; 3D Systems, Rock Hill, SC) and resectability of the tumor was determined (Figure 1, E). We planned RV mass removal with the aim of making a confirmative diagnosis and achieving curative resection.

After sternotomy, the base of the tumor was found at the inferior side over the right atrioventricular groove (Figure 2, $A$ ). Cardiopulmonary bypass was established via the ascending aorta, superior vena cava, and the right femoral vein. The right atrium was opened under a beating-heart state, and atrial-side tumor margin was demarcated. The aorta was crossclamped and then $1 \mathrm{~L}$ of del Nido solution was administered via an aortic root cannula.

The septoposterior commissure of tricuspid valve (TV) was completely divided to eliminate the tumor, and the posterior descending artery, which was entirely encircled by the tumor, was sacrificed. The inferior part of RV, atrial septum, and the coronary sinus orifice were defective after tumor resection. After direct closure of atrial septal defect, the $\mathrm{RV}$ wall was repaired by double-patch technique using bovine pericardial patch. The coronary sinus was recreated and then 


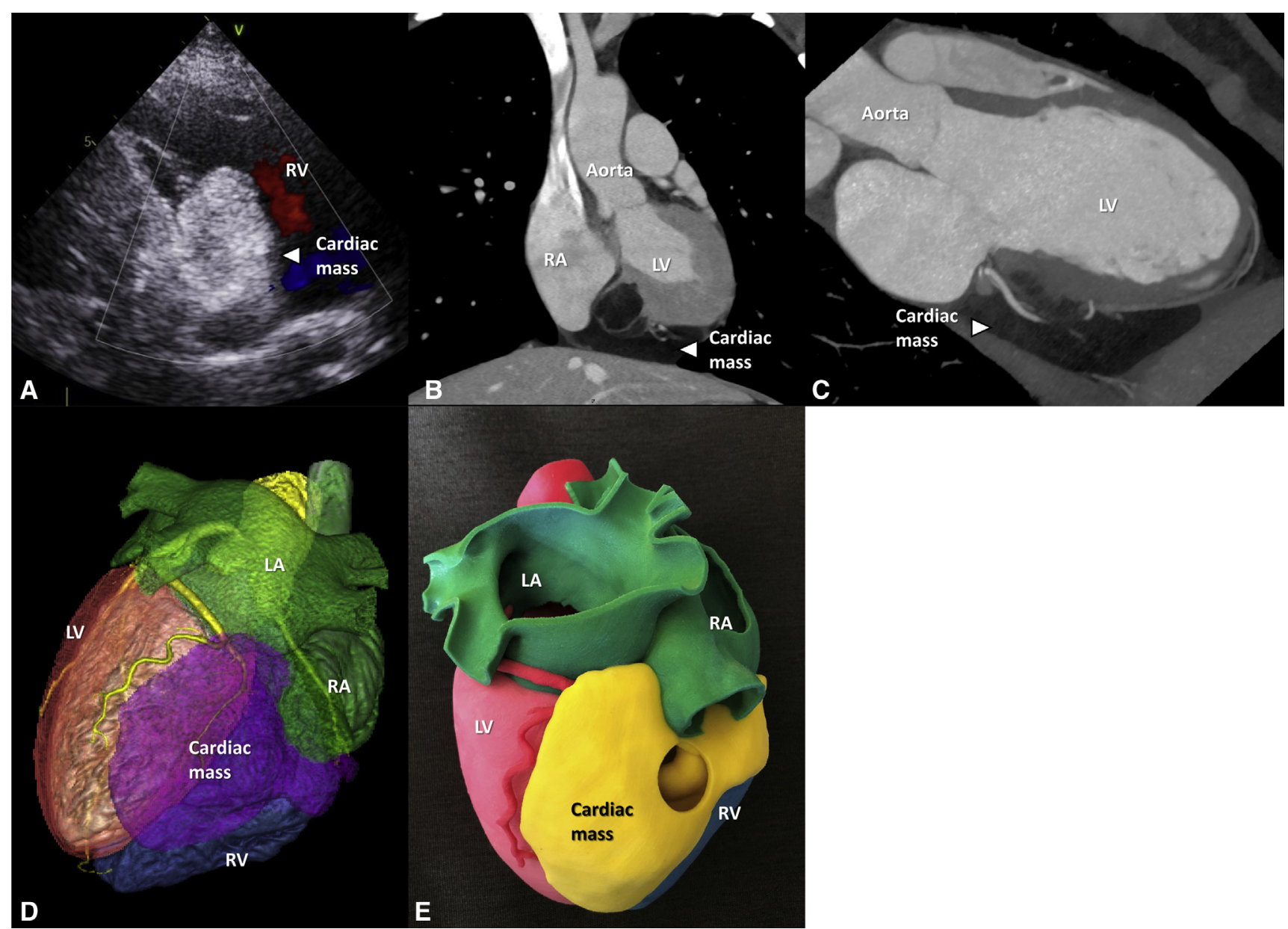

FIGURE 1. Preoperative image findings of cardiac tumor. A, Transthoracic echocardiographic image. B-D, Computed tomography image of the heart showing a cardiac mass measuring $66 \mathrm{~mm} \times 70 \mathrm{~mm} \times 40 \mathrm{~mm}$. E, Three-dimensional printing model. $R V$, Right ventricle; $R A$, right atrium; $L V$, left ventricle; $L A$, left atrium.

the right atrioventricular groove, right atrium, and inferior vena cava were reconstructed by single bovine pericardial patch. Gross structure of TV was restored after atrioventricular repair and a plication stitch was added to the septoposterior commissure (Video 1). The aortic crossclamping and cardiopulmonary bypass times were 77 and 90 minutes, respectively. Frozen section examination revealed all negative resection margins. Final pathologic examination verified lowgrade lipogenic tumor with clear resection margin and negative result of immunohistochemistry staining indicated lower possibility of well-differentiated liposarcoma. (Figure 2, B and $C$ ). Postoperative computed tomography and echocardiography revealed no residual mass (Figure 2,D). The patient was discharged on postoperative day 4 without perioperative complications.

The study was approved by the institutional review board of Asan Medical Center (IRB approval no., 2021-0640), and the statement of patient informed consent was written by the patient.

\section{COMMENT}

General principle in the treatment of primary cardiac tumor suggests that surgical resection should always be considered with priority to establish a confirmative diagnosis, offer chances of curative resection, and prevent later malignant transformation, unless there is a possibility of lymphoproliferative disorders where chemo-/radiotherapy are the firstline therapies. ${ }^{4}$ Incisional biopsy may trigger invasion to adjacent structures by disrupting the tumor and consequently reducing the chance of a disease cure; thus, complete resection should be the primary choice whenever possible. ${ }^{5}$ Referring to previous studies, out Heart Team decided to undergo complete resection after thorough discussion.

In the present case, the cardiac tumor was violating various structures including the $\mathrm{RV}, \mathrm{TV}$, and coronary artery branch, and 2-dimensional images provided insufficient information to surgeon to have comprehensive perceptions on anatomical relationship between the tumor and adjacent structures, and determine operability. The 3D-printing 


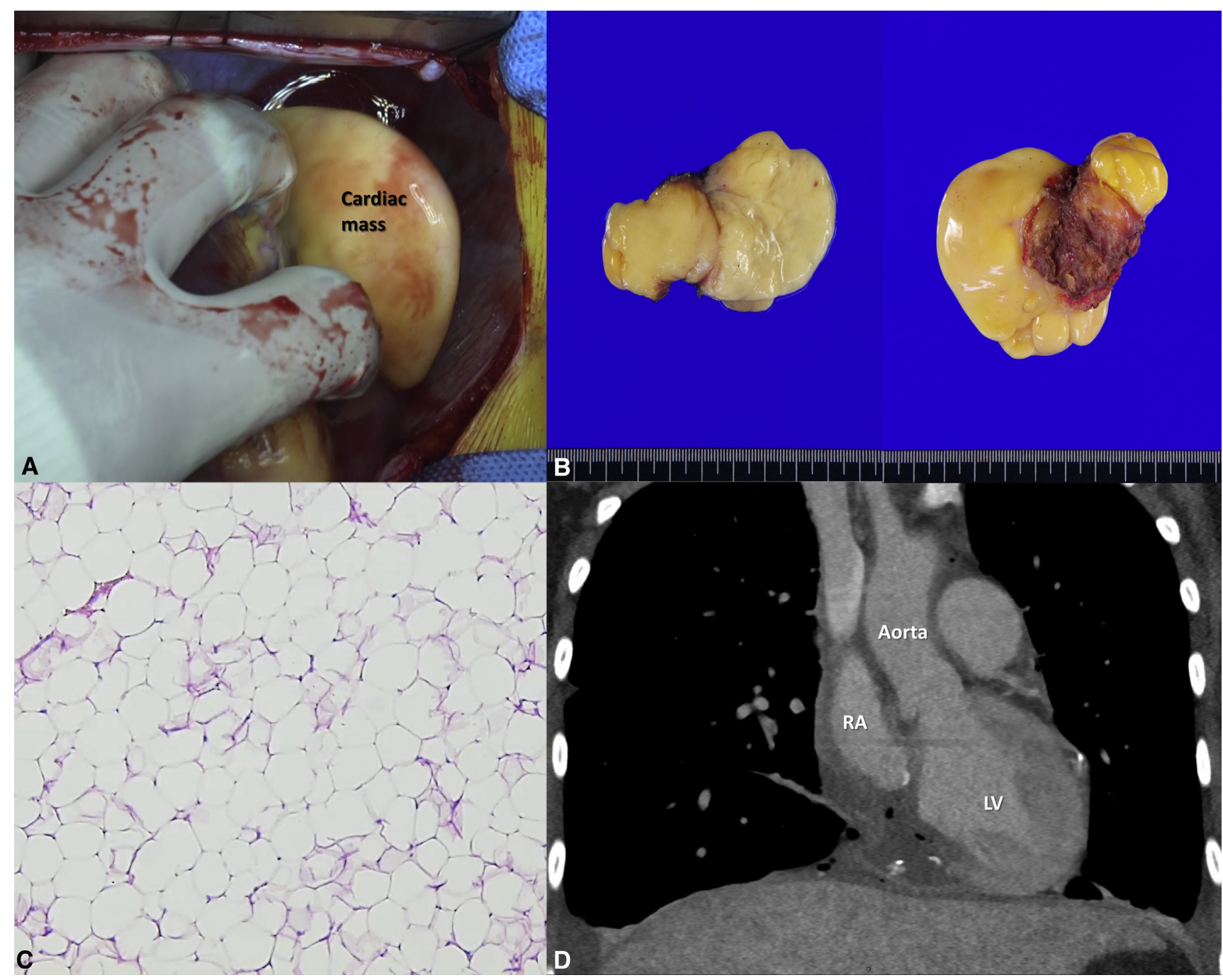

FIGURE 2. A, Cardiac tumor observed in the operative field. B, Gross appearance. C, Histopathologic findings of the cardiac tumor. D, Postoperative computed tomography image of the heart. $R A$, Right atrium; $L V$, left ventricle.

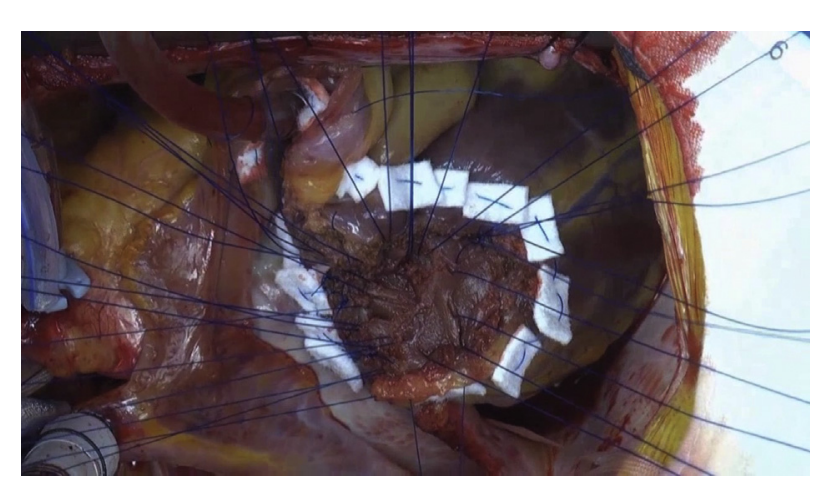

VIDEO 1. The video presents a brief introduction of the patient including preoperative imaging evaluation of the cardiac tumor, surgical procedure, and postoperative course. Video available at: https://www.jtcvs.org/ article/S2666-2507(21)00756-2/fulltext. model enabled surgeons to identify the tumor extension precisely and establish surgical strategy by repeated hands-on simulations. Based on various scenarios prepared preoperatively, we could operate on this complex cardiac mass with confidence and accomplish successful surgery by achieving complete resection with negative resection margins. We speculate the surgery might have not been executed if it had been determined inoperable depending upon the ordinary decision-making process considering its extensiveness and complexity. In conclusion, a 3D printing model may be an important guiding tool for determining operability and establishing surgical planning in complex cardiac tumors.

\section{References}

1. Castello J, Silvay G. Characterization and management of cardiac tumors. Semin Cardiothorac Vasc Anesth. 2010;14:6-20. 
2. Reece IJ, Cooley DA, Frazier OH, Hallman GL, Powers PL, Montero CG, et al. Cardiac tumors: clinical spectrum and prognosis of lesions other than classical benign myxoma in 20 patients. J Thorac Cardiovasc Surg. 1984;88:439-46.

3. Yang DH, Park S-H, Lee K, Kim T, Kim JB, Yun T-J, et al. Applications of threedimensional printing in cardiovascular surgery: a case-based review. Cardiovasc Imaging Asia. 2018;2:166-75.
4. MacGillivray TE, Reardon MJ. Surgical treatment of cardiac and pulmonary sarcomas. Op Tech Thorac Cardiovasc Surg. 2021;26:219-23.

5. Hirota M, Ishikawa N, Oi M, Tedoriya T. Large primary cardiac sarcoma on the left ventricular free wall: is total excision contraindicated? Interact Cardiovasc Thorac Surg. 2010;11:670-2. 